\title{
Driving Characteristics of Electric-Powered Wheelchair Users: How Far, Fast, and Often Do People Drive?
}

\author{
Rory A. Cooper, PhD, Tricia Thorman, MOT, OTR, Rosemarie Cooper, MPT, PT, Michael J. Dvorznak, BS, \\ Shirley G. Fitzgerald, PhD, William Ammer, BS, Guo Song-Feng, PhD, Michael L. Boninger, MD
}

ABSTRACT. Cooper RA, Thorman T, Cooper R, Dvorznak MJ, Fitzgerald SG, Ammer W, Song-Feng G, Boninger ML. Driving characteristics of electric-powered wheelchair users: how far, fast, and often do people drive? Arch Phys Med Rehabil 2002;83:250-5.

Objectives: To determine the driving characteristics of electric-powered wheelchair users during unrestricted community activities and to compare the activity levels among an active group and a group of regular users.

Design: Multisite engineering evaluation of electric-powered wheelchair driving activity during unrestricted community mobility.

Setting: Data were collected in the communities of Pittsburgh, PA, and the National Veterans Wheelchair Games (NVWG) in San Antonio, TX.

Participants: Seventeen people participated, all of whom used electric-powered wheelchairs as their primary means of mobility.

Intervention: Each subject was asked standarized questions about self and wheelchair use. Data logger and sensor installed on wheelchair. Data downloaded from logger.

Main Outcome Measures: Speed, distance traveled, and the time that each subject's personal wheelchair was being driven were recorded for $24 \mathrm{hr} / \mathrm{d}$ over approximately 5 days for each subject by using a custom-built data logger.

Results: The NVWG group traveled faster than the Pittsburgh group, but this difference was only statistically significant on the first day. The NVWG group was more likely to travel longer than the Pittsburgh group with significant differences seen in day $4(P=.03)$ and day $5(P=.05)$. Total distance traveled during the 5-day period and average distance traveled per day were also significantly different between the groups ( $P=.02$ for both 5-day distance and daily distance), with the NVWG group traveling longer $(17,164 \pm 8708 \mathrm{~m})$ when compared with the Pittsburgh group (8335 $\pm 7074 \mathrm{~m})$ over the 5-day period. Both distance traveled and speed increased during afternoon and evening hours. The maximum

From the Human Engineering Research Laboratories, VA Rehabilitation Research and Development Center, VA Pittsburgh Healthcare System (Cooper, Thorman, Cooper, Dvorznak, Fitzgerald, Boninger); and Departments of Rehabilitation Science \& Technology (Cooper, Thorman, Cooper, Dvorznak, Fitzgerald, Boninger), Physical Medicine \& Rehabilitation (Cooper, Cooper, Ammer, Boninger), and Bioengineering (Cooper, Dvorznak, Boninger), University of Pittsburgh, Pittsburgh, PA.

Accepted in revised form February 8, 2001.

Supported in part by Independence Technology, LLC, the VA Rehabilitation Research and Development Service, Veterans Health Administration, US Department of Veterans Affairs (grant no. F2181C), and the National Institute on Disability and Rehabilitation Research Rehabilitation Engineering Research Center on Wheeled Mobility, US Department of Education (grant no. H133E990001).

No commercial party having a direct financial interest in the results of the research supporting this article has or will confer a benefit upon the author(s) or upon any organization with which the author(s) is/are associated.

Reprint requests to Rory A. Cooper, PhD, Human Engineering Research Laboratories (151-R1), VA Pittsburgh Healthcare System, 7180 Highland Dr, Pittsburgh, PA

15206, e-mail: rcooper+@ @itt.edu.

0003-9993/02/8302-6590\$35.00/0

doi:10.1053/apmr.2002.28020 distance traveled by any subject for each hour across the 2 groups was used to create the theoretic maximum distance day, which resulted in $7970 \mathrm{~m}$ of driving.

Conclusion: Drivers of electric-powered wheelchairs are most active during the afternoon and evening hours. Over the 5-day period of this study, there was little variation in the speed or distance driven per day. The subjects participating in the NVWG were more active than their counterparts during a typical week at home. The maximum theoretic distance that a wheelchair user in our group would travel is less than $8 \mathrm{~km}$. The range of current electric-powered wheelchairs appears adequate, if not generous, for the subjects in our study.

Key Words: Community action; Rehabilitation; Wheelchairs.

(C) 2002 by the American Congress of Rehabilitation Medicine and the American Academy of Physical Medicine and Rehabilitation

$\mathbf{T}$ HERE IS VERY LITTLE information about the actual driving behavior of users of electric-powered wheelchairs. This information is critical for designing electric-powered wheelchairs, wheelchair components, battery design and specification, and in studies of risk exposure (eg, risk of injury because of component failure). Some of this information can be extrapolated from previous work. Winyard et $\mathrm{al}^{1}$ surveyed 100 users of electric-powered-wheelchairs to determine their wheelchairs' function and reliability. Wheelchair users who were most satisfied had previous wheelchair experience or lived in an institution. The results also showed that major modifications to the wheelchair to accommodate an individual's needs reduced wheelchair reliability. A majority of respondents reported long delays in repairs. Miles-Tapping and MacDonald $^{2}$ interviewed 11 current and future electric-powered wheelchair users between the ages of 35 and 85 years to determine their opinions on selection process and how the electric-powered wheelchair changed their lives.

For people who experience a traumatic impairment, the decision to use an electric-powered wheelchair is simply another of the number of decisions made during rehabilitation. In contrast, for people with progressive disabilities, the decision is usually more drawn out as the individual accommodates to the realization of an entirely new lifestyle. Batavia and Hammer ${ }^{3}$ used a modified Delphi method with 2 consumer focus groups. One group had mobility impairments, whereas another group had sensor impairments. The groups identified 17 factors to evaluate assistive devices. These factors are affordability, compatibility, consumer repairability, dependability, durability, ease of assembly, ease of maintenance, effectiveness, flexibility, learnability, operability, personal acceptability, physical comfort, physical security, portability, securability, and supplier repairability. These consumers ranked effectiveness, affordability, operability, and dependability highest. Kirby and Ackroyd-Stolarz 4 examined the Medical Device Reporting System database of the US Food and Drug Administration. A total of 651 records were analyzed covering the years 1975 to 1993. The study reported that there were 368 wheelchair-related in- 
juries, of which 21 were fatal. Most accidents occurred while driving a scooter $(52.8 \%)$ compared with electric-powered wheelchairs $(24.6 \%)$ and manual wheelchairs $(22.6 \%)$. Incidents could be attributed to design factors, environmental conditions, operator error, and the interactions of these conditions.

Kauzlarich et $\mathrm{al}^{5}$ used an indoor and outdoor driving course to determine the driving cycles of electric-powered wheelchairs. The results of the driving cycle tests were used to program bench-top equipment to cycle 4 types of batteries (gel-cell lead-acid, wet-cell lead-acid, nickel-cadmium, nickelzinc). Their results showed the wet-cell lead-acid battery offered the best performance and lowest cost. Garrett et $\mathrm{al}^{6}$ studied battery chargers for electric-powered wheelchairs to determine if battery chargers adequately charged wheelchair batteries over an 8-hour period and if they affected battery life. The study showed that there were clear differences in the performance and quality of the battery chargers available for electric-powered wheelchairs. Fisher et $\mathrm{al}^{7}$ showed that there is wide disparity in the performance of batteries and that over time the charge capacity of the 2 batteries within the wheelchair becomes unequal. Cooper et $\mathrm{al}^{8}$ estimated the range for 7 different electric-powered wheelchairs by using an International Organization for Standardization (ISO) double-drum tester and a motor-driven treadmill and by driving around a tennis court. The predicted range on the tennis court at maximum speed varied from 24 to $58 \mathrm{~km}$.

Butler et $\mathrm{al}^{9}$ provided 6 girls and 3 boys who had disabilities with conventional electric-powered wheelchairs operated by a hand-activated joystick. Parents were asked to keep a log of their child's activities, including recording the hours of operation of the wheelchair. Eight of the 9 children became independent in driving; the youngest was 24 months. Hours of operation to master all tasks required between 2 and 12 hours of driving time. The parents provided many anecdotes as to how electric-powered wheelchair driving helped their child's development.

Breed and Ibler ${ }^{10}$ presented their experiences surrounding prescription of electric-powered wheelchairs to 27 children ages 4 to 17 years. The following 4 general problem areas were identified: education of the wheelchair user, education of the general public about the use of an electric-powered wheelchair on public transportation systems, safety of wheelchair users and the general public in community spaces, and establishment of a legal status for wheelchair ambulating. Training of the electric-powered wheelchair user must include recognition of danger, caution, and planning. Drivers of motor vehicles should be made aware of the capabilities of electric-powered wheelchair users as a special class of pedestrians. Breed and Ibler ${ }^{10}$ reported that electric-powered wheelchairs need good designs, good construction, and good maintenance. They further suggested the use of visibility devices for motorists to see the wheelchair user, restraints to keep the user in the chair, and identity tags for the wheelchair. Butler et $\mathrm{al}^{11}$ also studied the ability of 13 children under age 4 to learn to drive an electricpowered wheelchair. All children were fitted for a personal electric-powered wheelchair. Parents kept daily logs of their child's wheelchair use and a meter kept track of hours of operation. Twelve children took an average of 34.4 hours (range, 6.6-168hr) to learn the electric-powered wheelchair driving skills prescribed for this study. The actual wheelchair driving time to master the skills was 8.1 hours on average (range, 1.7-26.1hr). In some children, there was a latency period before learning a new skill.

Our study sought to determine the driving characteristics of community-dwelling users of electric-powered wheelchairs. Data were collected on the distance traveled per day, average speed while driving, times when driving during the day, and distance traveled between battery charges. Data were collected from participants in the 20th National Veterans Wheelchair Games (NVWG), San Antonio, TX, and a group of electricpowered wheelchair users in Pittsburgh, PA. Because of the number of activities available to NVWG participants and ready access to transportation, it was anticipated that NVWG subjects would drive further, faster, and during more hours of the day than the Pittsburgh group during the data collection period. These data have important implications for the design of electric-powered wheelchairs and the design and selection of wheelchair batteries. The results also provide some guidance on charging electric-powered wheelchair batteries.

\section{METHODS}

\section{Subjects}

Seventeen electric-powered wheelchair users gave written informed consent to participate in this study. Subjects were recruited through United Cerebral Palsy Association of Allegheny County (Pittsburgh, PA) and on a "drop-in" basis at a booth of the exposition at the 20th NVWG, San Antonio, TX. There were 10 subjects in the NVWG group and 7 in the Pittsburgh group. Subjects included in the study used electricpowered wheelchairs because of spinal cord injury ( $n=3$ with paraplegia, $n=6$ with tetraplegia), multiple sclerosis $(n=1)$, spina bifida $(\mathrm{n}=1)$, polio $(\mathrm{n}=1)$, head injury $(\mathrm{n}=1)$, muscular dystrophy $(\mathrm{n}=1)$, lower motor neuron disease $(\mathrm{n}=$ $1)$, or cerebral palsy $(n=2)$. Eleven of the subjects were men; 7 were women. The subjects had been using electric-powered wheelchairs for a mean \pm standard deviation (SD) of $14.5 \pm$ 11.5 years. All subjects used them as their primary means of mobility within the community. The type and characteristics of personal wheelchairs used by the subjects who participated in this study are presented in table 1 . All of the wheelchairs included in this study were rear-wheel drive with front casters, and all of the wheelchair batteries were sealed lead-acid.

\section{Instrumentation and Data Reduction}

The data logger used in this study was based on a TFX-11 single board computer, ${ }^{\mathrm{a}}$ which was mounted in a specially designed box created by the authors. ${ }^{12}$ The enclosure was designed to be tamper, shock, and water resistant (fig 1). The mass of the data logger and sensors is less than $0.5 \mathrm{~kg}$. The data logger was designed to collect up to 2 weeks of data at a sampling rate of 1 second or 100,000 time stamps. The sampling rate was selected so that the maximum speed of the wheelchair could be recorded without running the risk of overflowing the memory during the collection period, assuming that the user traveled at the wheelchair's maximum theoretic range each day. A ceramic permanent magnet was adhered to the tire or hub of each wheelchair tested. A reed switch was attached to the frame of each wheelchair tested and each time the magnet passed the reed switch, the time was stored to the nearest second. The output of the reed switch was input to a simple passive debounce circuit to eliminate erroneous switch closures. The data logger was attached to each subject's wheelchair by a hook and loop band. The recordings from the data logger were downloaded to a personal computer. Data were analyzed by using software written in MATLAB ${ }^{\odot} .{ }^{c}$ Each data stamp represents a revolution of a rear wheel; data were recorded from a single wheel on each wheelchair. The total distance traveled $(D)$ is equal to number of date stamps $(N)$ times the wheel circumference $(C)$ :

$$
D=N \cdot C
$$


Table 1: Characteristics of Study Wheelchairs

\begin{tabular}{|c|c|c|c|}
\hline & Pittsburgh Group ( $\mathrm{n}=7$ ) & NVWG Group $(n=10)$ & Combined $(\mathrm{N}=17)$ \\
\hline Power wheelchair use (y) & $20.3 \pm 11.0$ & $10.4 \pm 10.1$ & $14.5 \pm 11.5$ \\
\hline Wheel diameters $(\mathrm{cm})$ & $35.9 \pm 6.5$ & $30.3 \pm 4.0$ & $32.5 \pm 5.7$ \\
\hline K0011 class & 4 & 3 & 7 \\
\hline K0014 class & 3 & 7 & 10 \\
\hline \multirow[t]{8}{*}{ Wheelchairs used (no.) } & E\&J Ranger ${ }^{\mathrm{e}}(2)$ & Action Arrow Storm (4) & E\&J Ranger (2) \\
\hline & Action Arrow ${ }^{\circledR}$ Storm $^{f}(3)$ & Quickie P200 (2) & E\&J Navigator (1) \\
\hline & Quickie $^{\mathrm{g}}$ S525 (1) & Action Ranger $X^{\oplus M}$ Storm $^{f}(2)$ & Action Arrow Storm (7) \\
\hline & E\&J Navigator ${ }^{\mathrm{e}}(1)$ & Action Storm ${ }^{\circledR} \mathrm{GB}^{\mathrm{f}}(1)$ & Action Ranger X Storm (2) \\
\hline & & Quickie P300 (1) & Action Storm GB (1) \\
\hline & & & Quickie P200 (2) \\
\hline & & & Quickie P300 (1) \\
\hline & & & Quickie S525 (1) \\
\hline
\end{tabular}

The distance traveled during each hour $\left(D_{\text {hour }}\right)$ was determined by simply computing the number of time stamps $\left(n_{\text {hour }}\right)$ during the hour and multiplying the count by the wheel circumference:

$$
D_{\text {hour }}=C \cdot n_{\text {hour }}
$$

The speed between time stamps $(v)$ was determined by dividing the wheel circumference by the difference between the current time stamp, $t(i)$, and the next time stamp, $t(i+1)$ :

$$
v=\frac{C}{t(i+1)-t(i)}
$$

The variables described by equations 1 through 3 were used to characterize the electric-powered wheelchair driving behavior and to compare the Pittsburgh group with the NVWG group. We also examined the hours within each day that driving occurred.

\section{Protocol}

Subjects were asked a series of standardized questions to collect descriptive characteristics about them and their wheelchair. Then the data logger and sensor were installed on each subject's personal wheelchair. The operation of the data logger was verified by one of the study investigators. The subjects were instructed to disregard the data logger and to pursue their

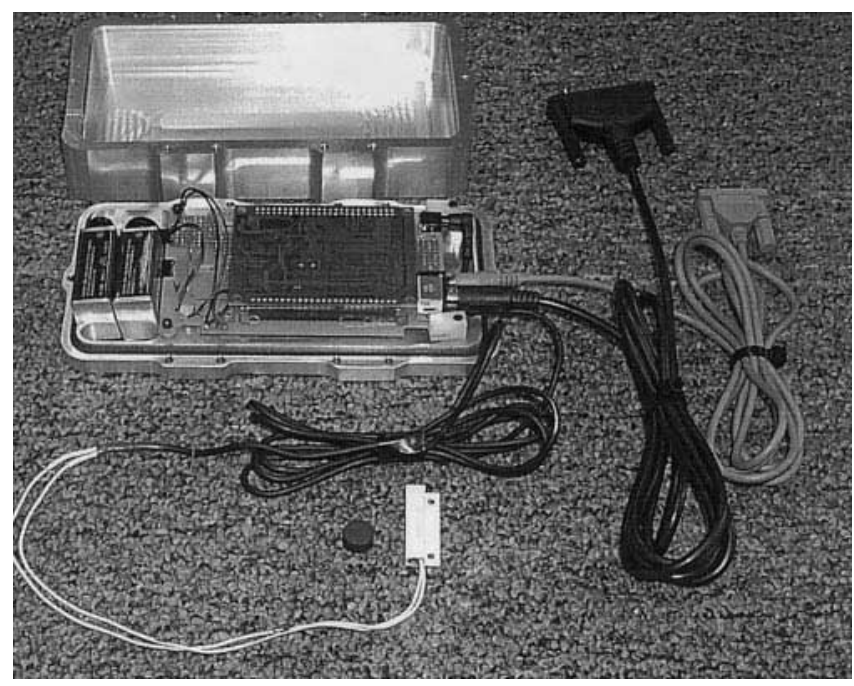

Fig 1. Data logger. normal activities. Subjects were given a telephone number to reach the investigators to report any problems or to request removal of the data logger. None of the subjects requested to withdraw or were withdrawn from the study.

Subjects at the NVWG were asked to allow an investigator to download data every day. This was typically done by meeting each subject at one of the sports venues or where meals were served to NVWG participants. This allowed us to reduce the risk of data loss because of a failure in the instrumentation. The data from the Pittsburgh group were downloaded between 5 and 7 days postinstallation of the data loggers. Data were first collected from the NVWG group and then a few weeks later from the Pittsburgh group. Data collection for both groups started on a Monday and ended on either the following Saturday or Monday, whichever was most convenient for the subject. Only the first 5 complete days of data were analyzed. Collecting data simultaneously would have required more data loggers and study personnel than were available. Data from subjects within a given group were collected at nearly the same time, give or take 4 hours. All data were collected during July and August 2000.

\section{Statistical Analysis}

Descriptive statistics were completed for speed and distance traveled for each hour of the day as well as over a 24-hour period of the 5-day trial period. Averages for distance, speed, and actual time (hr) driving were calculated across the 5 days to obtain a typical day. Similarly, for each hour of each day an average distance and speed was obtain to provide a profile for hours across days. The maximum distance traveled and time spent driving during each hour were determined and a worstcase day was graphed for the maximum distance traveled. Comparisons were made between the NVWG group and the Pittsburgh group for speed, distance, time spent driving, and demographic differences. Demographic characteristics included age, years in a power wheelchair, and type of power wheelchair as defined by the Medicare K codes. ${ }^{13}$ Comparisons were also made between type of wheelchair (Medicare $\mathrm{K}$ codes) and speed as well as wheelchair and distance.

Because the sample size was small, nonparametric statistics were used to determine significant differences. To determine differences between the 2 groups and continuous variables (ie, age, speed, distances) the Mann-Whitney $U$ test was used. To determine whether differences existed between categoric variables (class of wheelchair, group) the Fisher exact chi-square test was used because some of the cells had fewer than 5 data points. All data were analyzed by using SPSS. ${ }^{\text {I }}$ It was hypoth- 
Table 2: Comparison of Demographic Factors Between NVWG and Pittsburgh Groups

\begin{tabular}{lccc}
\hline \multicolumn{1}{c}{ Variable } & NVWG & Pittsburgh & $P$ \\
\hline $\begin{array}{l}\text { Age (mean } \pm \text { SD) } \\
\text { Years in wheelchair } \\
\text { (mean } \pm \text { SD) }\end{array}$ & $46.9 \pm 9.5$ & $49.6 \pm 6.2$ & .463 \\
K11 wheelchair users (\%) & $10.4 \pm 10.1$ & $20.3 \pm 11.0$ & .045 \\
\hline
\end{tabular}

esized that the participants in the NVWG would yield significant differences $(P<.05)$ in the study variables compared with the Pittsburgh group.

\section{RESULTS}

Table 2 shows the comparison of demographic factors between both groups. There were no significant differences between average age and type of power wheelchair used. Years in wheelchair were significantly different, with the NVWG having fewer years than the Pittsburgh group. This may be a result of the small sample size or because the individuals who were in the NVWG group were more likely to have experienced a spinal cord injury (80\%) than participants in the Pittsburgh group (43\%). Participants in the Pittsburgh group were more likely to have a diagnosis of cerebral palsy or multiple sclerosis, which may affect the years of power wheelchair use.

The results from the data logger are summarized in table 3. Figure 2 shows the average speed when driving (subjects were determined to be stopped if no signal was received within $1 \mathrm{~min}$ ) each day obtained over the 5-day period. The NVWG group traveled faster than the Pittsburgh group, but this difference was only statistically significant on the first day. Similarly, figure 3 shows the average distance traveled between the groups each day over the 5-day period. The NVWG group was more likely to travel farther than the Pittsburgh group, with significant differences seen in day $4(P=.03)$ and day $5(P=$ $.05)$. Total distance traveled during the 5-day period and average distance traveled per day were also significantly different between the groups $(P=.02$ for both 5-day distance and daily distance), with the NVWG group traveling further (17164 \pm $8708 \mathrm{~m})$ when compared with the Pittsburgh group (8335 \pm $7074 \mathrm{~m}$ ) over the 5-day period. There were no significant differences between type of wheelchair and distance or speed traveled over the 5-day period.

Figures 4 and 5 show the mean and 1 SD distance traveled per hour of study day and average speed. There appears to be moderate activity almost 24 hours a day, except between 1:00 $\mathrm{AM}$ and 5:00 AM. The NVWG group traveled further at faster speeds than the Pittsburgh group. Figure 6 shows the maximum distance traveled by any subject for each hour across the 2 groups. The total distance traveled over this theoretic maximum distance day was $7970 \mathrm{~m}$.

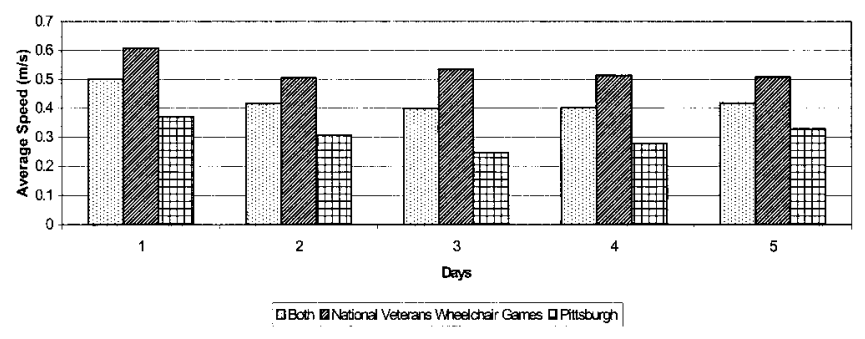

Fig 2. Average speed across days.

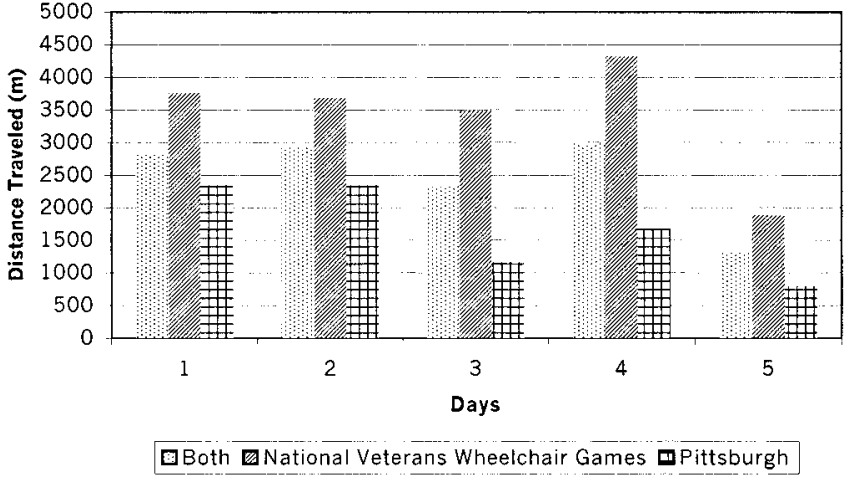

Fig 3. Average distance across days.

\section{DISCUSSION}

We hypothesized that the participants in the NVWG would be more active than a sample of community-dwelling drivers of electric-powered wheelchair users. We based our hypothesis on the assumption that the large number of activities open to the participants, readily available transportation, and the camaraderie among the participants would encourage high activity among users of electric-powered wheelchair users. This appears to be the case; the NVWG group went further and faster than the Pittsburgh group on a daily and 5-day basis. On the other hand, individuals who are more active may be more likely to participate in the NVWG. The NVWG group drove nearly twice the distance as the Pittsburgh group over the 5-day sampling periods. The NVWG group was more active than the Pittsburgh group later into the evening hours, a further indication of the activities available to the NVWG participants. Both groups showed peak of activity (indicated by average hourly speed and average hourly distance) during the afternoon and early evening hours.

The maximum speed of each subject's electric-powered wheelchair was approximately $2.7 \mathrm{~m} / \mathrm{s}$. The subjects drove their wheelchair considerably less than the wheelchair's maximum speed most of the time, even when only the actual driving time was used to determine the average speed. The capacity for the wheelchair to drive at or near $2.7 \mathrm{~m} / \mathrm{s}$ was used for short spurts of a few meters. This is likely related to crossing intersections, avoiding pedestrians, and other similar maneuvers. Of course, some of the bouts of near maximum or maximum speed driving for the NVWG group were during competition.

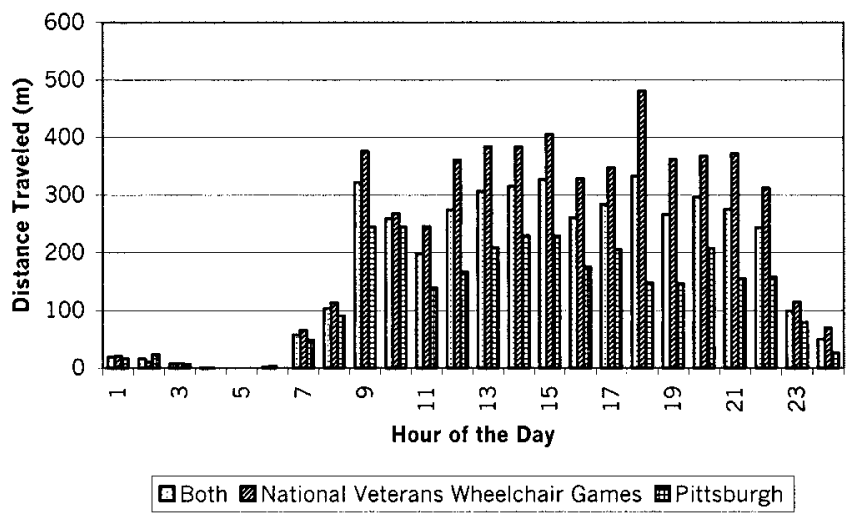

Fig 4. Average distance traveled within 24 hours. 


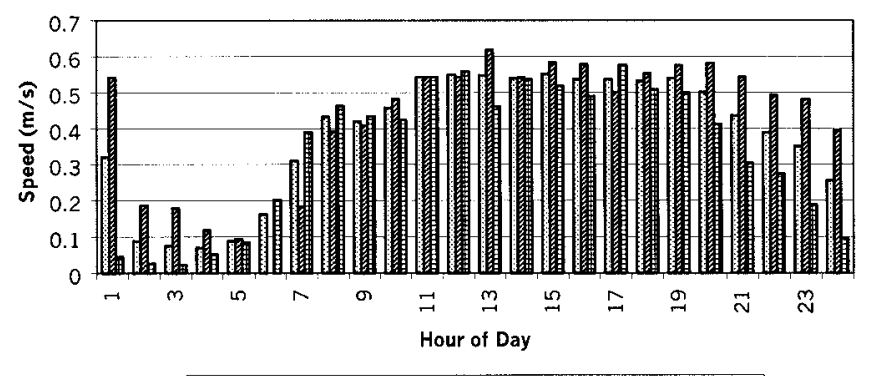

Both $\mathbb{O}_{\text {National Veterans Wheelchair Games }}$ Pittsburgh

Fig 5. Average speed traveled within 24 hours.

We asked the subjects to report the frequency of charging their batteries. The overwhelming majority of the subjects reported charging their wheelchair batteries daily. Hence, the daily driving behavior is essentially equivalent to the driving behavior between charging periods. All of the subjects charged their wheelchair batteries in the evening and nighttime hours. This is reflected in the reduction in activity presented in figures 4 and 5 during charging hours. Different styles of wheelchairs sometimes use different size batteries. To investigate whether there was an effect on driving behavior based on electricpowered wheelchair type, we compared wheelchairs in the Medicare K0011 with the K0014 groupings. We found no significant differences in any of the study variables, although Cooper et $\mathrm{al}^{8}$ previously reported that K0014 wheelchairs tend to have a longer theoretic range than K0011 wheelchairs.

It is very important that drivers of electric-powered wheelchairs not get stranded because of inadequate battery capacity. However, the size and mass of the batteries play an important role in the design of the electric-powered wheelchair. The American National Standards Institute (ANSI), Rehabilitation Engineering and Assistive Technology Society of North America (RESNA), and the ISO have tests for both the durability and theoretic range per battery charge for electric-powered wheelchairs. Cooper ${ }^{8}$ reported that common electric-powered wheelchairs have a range of 24,000 to $58,000 \mathrm{~m}$; these range values were for ideal conditions (eg, flat and level surface, moderate ambient temperature, well-conditioned batteries).

The results from our study show that the optimal range is about 5 times the maximum distance that drivers of electricpowered wheelchairs actually traverse. We created a variable termed the "theoretic maximum distance day" by summing the maximum distance traveled each hour of the day by any subject within our study. This variable yielded a maximum $7970 \mathrm{~m}$ for a day or about one third the optimum maximum range (as determined by the ANSI/RESNA-ISO test) for the wheelchair with the lowest range in the Cooper ${ }^{8}$ study. This indicates that the battery capacity and likely the mass are larger than they may need to be. It is noteworthy that both Pittsburgh and San Antonio have substantial changes in elevation within their communities.

Electric-powered wheelchairs are commonly replaced every 3 to 5 years. After this amount of time, the electric-poweredwheelchair has reached the end of its useful life, and it is safer and less expensive to replace it. Based on this life, the ANSI/ RESNA-ISO fatigue tests were developed to determine whether a wheelchair would be safe and effective over the expected 3 to 5 years of use. The standards require a minimum of 200,000 double-drum cycles and 6666 curb-drop cycles to comply. ${ }^{14}$ The ratio of these 2 numbers is $1 / 30$, which can be used to determine equivalent cycles. If we assume that 400,000 equivalent cycles (ie, combined double-drum and curb-drop) represents 3 to 5 years of use, a persistent question that remains is how many actual driving miles does that represent? Based on the results of our study, an estimate was determined. Three years of use likely represents a very active user; hence, we determined the distance that a person $1 \mathrm{SD}$ above the mean of the NVWG group would travel in 3 years driving every day. This wheelchair would be driven about $5666 \mathrm{~km}$ in 3 years. If we use the "theoretic maximum distance day," the wheelchair would be driven about $8727 \mathrm{~km}$ in 3 years.

The typical wheelchair user replaces the wheelchair about every 5 years. Hence, we determined the distance traveled over 5 years by using the average distance traveled per day by the Pittsburgh group. This wheelchair would be driven about $3042 \mathrm{~km}$ before replacement. Based on these estimates of the distance traveled during an electric-powered wheelchair's useful life, the ANSI/RESNA-ISO fatigue test equivalent cycles represent between 46 cycles $/ \mathrm{km}$ and 131 cycles $/ \mathrm{km}$. Just like any other vehicle, the combinations of hours of operation, miles, and the type of miles (eg, start-stop, continuous, pavement) all contribute to the life of the wheelchair.

This study provides some of the first data recorded on the actual usage of community dwelling users of electric-powered wheelchairs. The results have some important implications for the design and selection of batteries and other potential power sources. Given the information from this study and the energy and power requirements of their wheelchair, a wheelchair manufacturer can select the optimal battery. During this study, we were unable to collect data on the wheelchair operating current and battery voltage that could prove useful in the selection or design of batteries for existing wheelchairs. Future studies should collect data from both wheels to determine the amount of time spent turning versus going straight. In addition, the sensors need to be modified to detect whether the wheelchair is driving forward versus reverse. The addition of an inclinometer would allow the study of the distance driven while negotiating ramps, curb-cuts, and slopes. Data could also be collected during different seasons of the year to determine seasonal variations in driving behavior; however, it is likely that summer will yield the maximum average distance traveled per day. It was difficult for the subjects to recall the age of their wheelchair batteries; hence, no useful data was collected on battery age. Access to the wheelchair maintenance records would have been helpful. Data also need to be collected on children and adolescents as well as on groups of people with different disability origins.

\section{CONCLUSION}

Drivers of electric-powered wheelchairs are active most of the day, with the most common period of inactivity being

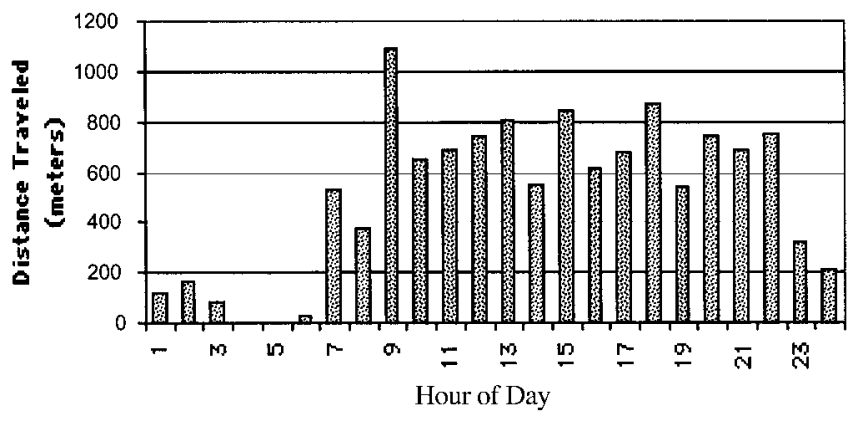

Fig 6. Maximum usage day. 
between 1:00 AM and 5:00 AM. Over the 5-day period of this study, there was little variation in the speed or distance driven per day. The subjects participating in the NVWG were more active than their counterparts during a typical week at home. The maximum theoretic distance that a wheelchair user in our group would travel is less than $8 \mathrm{~km}$. The range of current electric-powered wheelchair appears adequate for the subjects in our study.

\section{References}

1. Winyard GP, Luker C, Nichols PJ. The uses and usefulness of electrically powered indoor wheelchairs. Rheumatol Rehabil 1976;15:254-63.

2. Miles-Tapping C, MacDonald LJ. Lifestyle implications of power mobility. Phys Occup Ther Geriatr 1994;4(2):31-49.

3. Batavia AI, Hammer GS. Toward the development of consumerbased criteria for the evaluation of assistive devices. J Rehabil Res Dev 1990;27:425-36.

4. Kirby RL, Ackroyd-Stolarz SA. Wheelchair safety-adverse reports to the United States Food \& Drug Administration. Am J Phys Med Rehabil 1995;74:308-12.

5. Kauzlarich JJ, Ulrich V, Bresler M, Bruning T. Wheelchair batteries: driving cycles and testing. J Rehabil Res Dev 1983;20:3143.

6. Garrett RE, Hartridge M, Seeger BR. Comparative evaluation of chargers for wheelchair gel cell batteries. Aust Phys Eng Sci Med 1990;13:148-56.

7. Fisher WE, Garrett RE, Seeger BR. Testing of gel-electrolyte batteries for wheelchairs. J Rehabil Res Dev 1988;25:27-32.

8. Cooper RA, VanSickle DP, Albright SJ, Stewart KJ, Flannery M,
Robertson RN. Power wheelchair range testing and energy consumption during fatigue testing. J Rehabil Res Dev 1995;32:25563.

9. Butler C, Okamotot GA, McKay TM. Powered mobility for very young disabled children. Dev Med Child Neurol 1983;25:472-4

10. Breed AL, Ibler I. The motorized wheelchair: new freedom, new responsibility and new problems. Dev Med Child Neurol 1982; 24:366-71.

11. Butler C, Okamoto GA, McKay TM. Motorized wheelchair driving by disabled children. Arch Phys Med Rehabil 1984;65:95-7.

12. Spaeth DM, Arva J, Cooper RA. Application of a commercial datalogger for rehabilitation research. In: Proceedings of the 23rd Annual RESNA Conference Technology for the New Millenium. Orlando (FL); 2000 June 28-July 2. p 313-5.

13. HCFA Common Procedure Coding System (HCPCS). Available at: http://www.hcfa.gov/medicare/hcpcs.hmt. Accessed July 17 2001.

14. Cooper RA. Wheelchairs: a guide to selection and configuration. New York: Demos Medical; 1998.

\section{Suppliers}

a. Onset Computer Corp, 470 MacArthur Blvd, Bourne, MA 02532.

b. McMaster-Carr Supply Co, PO Box 94930, Cleveland, OH 441014930.

c. The MathWorks Inc, 24 Prime Park Way, Natick, MA 01760.

d. SPSS Inc, $233 \mathrm{~S}$ Wacker Dr, 11th Fl, Chicago, IL 60606-6307.

e. Graham-Fields, Everest \& Jennings, 1100 Corporate Sq Dr, St Louis, MO, 63132.

f. Invacare Corp, 899 Cleveland St, Elyria, OH, 44035.

g. Sunrise Medical Inc, 2842 Business Park Ave, Fresno, CA 937271328 